\title{
INVESTORS' PORTFOLIO BEHAVIOR UNDER ALTERNATIVE MODELS OF LONG-TERM INTEREST RATE EXPECTATIONS: UNITARY, RATIONAL, OR AUTOREGRESSIVE
}

\author{
By Benjamin M. Friedman and V. Vance Roley ${ }^{1}$
}

\begin{abstract}
This paper develops behavioral relationships explaining investors' demands for longterm bonds, using three alternative hypotheses about investors' expectations of future bond prices (yields). The results, based on U.S. "data for six major categories of bond market investors, consistently support an autoregressive expectations model. The results also have implications for further aspects of investors' portfolio behavior, including expectations formation, response to inflation, and speed of adjustment.
\end{abstract}

The DISTINGUISHING CHARACTERISTIC of a long-term asset, in contrast to a short-term asset, is the possibility of future movements of the asset's price. In the simplified but familiar context of nominally denominated fixed-income financial assets, for example, wealth or rate-of-return maximizing investors cannot choose between one-period securities and multi-period securities without at least implicitly relying on some expectation of the multi-period security's future price. ${ }^{2}$ Both economists and financial market participants well appreciate the crucial role which such expectations play in portfolio allocation decisions. ${ }^{3}$ Nevertheless, the nature of the process which determines these all-important expectations remains largely unknown. Many economists who have done empirical research on the term structure of interest rates have based their models on a maintained hypothesis involving some form of adaptive expectations assumption, but have not explicitly tested this hypothesis against plausible alternatives. ${ }^{4}$ Furthermore, empirical research on this question has at best been vague about the way in which investors' portfolio behavior presumably responds to their interest rate expectations.

The object of this paper is to investigate more explicitly, within the limited context of investment in long-term bonds, the formation of investors' expectations. Specifically, this paper tests, using U.S. data, three alternative hypotheses about investors' expectations of future long-term bond prices (yields): (i) Expectations are unitary if the expected future price is identical to the currently prevailing price. (ii) Expectations are rational if the actual future price is distributed about the expected future price with zero bias. (iii) Expectations are autoregressive if the expected future price is a function of currently and previously prevailing prices.

${ }^{1}$ The authors are grateful to Gary Chamberlain, Franklin Fisher, Zvi Griliches, John Lintner, Franco Modigliani, and two anonymaus referees for helpful comments on a previous draft, and to the National Science Foundation and the National Bureau of Economic Research for research support. This paper does not necessarily represent the views of the Federal Reserve Bank of Kansas City or the Federal Reserve System.

${ }^{2}$ Alternatively, an investor would need to have an expectation of the yield on one-period securities in each time period until the multi-period security's maturity. If the two securities were perfect substitutes, so that investors' arbitrage trading enforced at all times the term-structure equilibrium condition of Hicks [20] and Lutz [27], expectations about future prices of multi-period securities and expectations about future yields on short-term securities would be equivalent.

3 See Stiglitz [54] for a clear theoretical exposition.

- See, for example, Meiseiman [31], Modigliani and Sutch [35, 36], and Modigliani and Shiller [34]. 
Since the expectations in question are unobservable, in order to investigate their properties it is necessary to construct tests involving observable magnitudes upon which it is plausible to postulate that these expectations exert some influence. This paper follows previous researchers in choosing financial market behavior as the realm in which unobservable interest rate expectations may most plausibly have an observable effect. ${ }^{5}$ Instead of using the familiar "term-structure" approach of testing these three expectations hypotheses by imbedding them in unrestricted reduced-form equations relating the yields on different securities, however, this paper examines them in the context of behavioral relationships directly explaining investors' demands for bonds. In assessing the results of these tests, therefore, it is interesting to consider the implications not just for expectations formation but for more general aspects of portfolio behavior as well.

Section 1 explains the three alternative hypotheses about the formation of expectations, motivating each by an intuitive statement of its basic rationale together with references to its rigorous development in the theoretical literature (as well as previous empirical applications). Section 2, which draws on the authors' previous work on portfolio behavior, briefly develops the bond demand relationship to be used to test the competing expectations hypotheses. After a short summary of estimation issues in Section 3, Section 4 summarizes the results of estimating the bond demand relationship under each of the three expectations hypotheses and also presents the results of specific pairwise comparisons, using disaggregated data for the six principal categories of investors in the U.S. bond market. To anticipate, these results consistently support the autoregressive expectations hypothesis. Section 5 goes on to examine the implications of the estimated bond demand equations for further aspects of expectations formation and portfolio behavior. Here the results strongly imply either that investors are highly risk averse in a specific way, or that investors expect bond yields to return quickly to their long-run level after observed departures from that level. Additional results provide information about the way in which price inflation affects nominal interest rates, and about the speed of investors' portfolio adjustment out of equilibrium. Section 6 briefly summarizes the paper's conclusions.

\section{THREE HYPOTHESES ABOUT EXPECTATIONS}

The focus of attention in this paper is investors' expectations about uncertain asset returns-in particular, about the returns to long-term bonds-and the way in which such expectations influence investors' portfolio behavior. In the absence of default, the holding-period yield on a pure discount instrument with term to maturity equal to the investor's holding period is known exactly. By contrast, in a world of uncertainty all other instruments have unknown holding-period yields, even in the absence of default risk. In the case of an instrument with term to maturity longer than the investor's holding period, the uncertainty (sometimes

\footnotetext{
${ }^{5}$ In addition to the researchers cited in footnote 4, who used either adaptive or generalized autoregressive expectations in this way, see, for example, Nelson [40], Hamburger and Platt [19], and Phillips and Pippinger [42, 43].
} 
called "capital" uncertainty ${ }^{6}$ ) arises from the need to sell the instrument at a price which may differ from its par value. In the case of an instrument with term to maturity shorter than the investor's holding period, the uncertainty (sometimes called "income" uncertainty) arises from the need to re-invest the proceeds of the instrument's repayment at a yield which may differ from that currently prevailing. ${ }^{7}$

An analytical device which many researchers have used to simplify the analysis of investors' portfolio behavior is the assumption that, at the margin of their investment allocation decisions, investors act as if they have a one-period holding period. The convenience of this assumption is that it telescopes a multi-period problem, involving expectations of prices and yields many periods ahead, into a semi-myopic problem seemingly involving expectations only one period ahead. ${ }^{8}$ For any long-term asset like bonds, the relevant (stochastic) holding-period yield at time $t$ is simply

$$
\tilde{r}_{t}=c_{t}+\tilde{g}_{t+1}
$$

where $c_{t}$ is the asset's coupon, dividend or discount yield (which is known at time $t$, in the absence of default risk), and $\tilde{g}_{t+1}$ is the capital gain or loss component of the yield defined as ${ }^{9}$

$$
\tilde{g}_{t+1} \equiv \frac{\tilde{p}_{t+1}-p_{t}}{p_{t}}
$$

for $p$ the price of the asset. Since investors cannot act on the basis of information that they do not have, what matters in the first instance is their corresponding expectation

$$
r_{t}^{e}=c_{t}+g_{t+1}^{e}
$$

where the $e$ superscript indicates an expectation as of time $t$.

The issue, then, is investors' expectations of the one-period capital gain (or loss) associated with assets of more than one-period maturity. How do investors form these expectations? In the context of long-term bonds, at least three distinct-but

'See, for example, Leijonhufvud [22]. The distinction drawn in this paragraph is again that which Stiglitz [54], for example, has analyzed.

${ }^{7}$ In addition, as Nelson [40] has emphasized, in the case of coupon-bearing (or dividend-paying) instruments an additional source of uncertainty arises from the need to re-invest proceeds received before the instrument's maturity.

${ }^{8}$ A large literature has investigated the conditions (such as constant relative risk aversion, as ascumed in Section 2) which, within the more general framework of expected utility maximization, are su:-ient to render multi-period behavior myopic and hence analytically equivalent to single-period behavior; see, for example, Mossin [37] and Fama [7], and the useful review provided by Melton [32]. Examples of the myopic-allocation assumption in empirical work include the references cited in footnote 4, portfolio models in the tradition of Brainard and Tobin [3], as well as many others in the monetary economics and finance literatures.

${ }^{9}$ If the $\vec{g}$ is measured in a time unit different from the time period indicated by subscript $t$, it is necessary to adjust the right-hand side of (2) by some constant. In Section 2, for example, multiplication by 4 converts quarterly capital gains into annual rates. 
not necessarily mutually exclusive-hypotheses describing expectations formation have sufficient a priori plausibility to warrant empirical testing:

Unitary Expectations: The simplest hypothesis to implement follows from the typical (but not necessarily implied) interpretation of the large body of work associated with the "efficient markets" literature. ${ }^{10}$ To an approximation that is often treated as exact, a standard interpretation of this research implies that the prior expectation of the price change for a long-term asset (with a current income yield) is just zero, i.e.,

$$
g_{t+1}^{e}=0,
$$

because all available information about the asset's expected future price is already incorporated into the asset's current price; in Samuelson's [47] words, "... properly anticipated prices fluctuate randomly." Hence any change in realized prices generates a one-for-one change in expected future prices. Hicks [20], writing years before the development of the modern efficient markets literature, labeled such expectations "unitary."

Rational Expectations: A second hypothesis, due to Muth [39], is that economic agents in general form subjective expectations identical to the objective expectations of the true process generating the outcomes in question, conditional on all information available at the time. Hence the actual outcome for the stochastic asset yield is distributed around investors' prior expectation of it, just as any outcome is distributed around its mathematical expectation, i.e.,

$$
\tilde{\boldsymbol{g}}_{t+1}=\boldsymbol{g}_{i+1}^{e}+\tilde{\boldsymbol{u}}_{t+1}
$$

where $\tilde{u}$ is a zero-mean finite-variance random disturbance which is serially uncorrelated as well as uncorrelated with $g_{i+1}^{e}$. The motivation adduced by Muth in support of this hypothesis is that "rational" (i.e., optimizing) economic agents will efficiently exploit all available information and will therefore form unbiased predictions. ${ }^{11}$ Recent researchers have broadly applied the rational expectations hypothesis, especially in the context of macroeconomic policy. ${ }^{12}$

Autoregressive Expectations: Nerlove [41], Mincer [33], Box and Jenkins [2], and others have extensively investigated the problem of the optimal linear prediction of a stochastic time series from its own past history. For stationary time series, such predictions are in general expressible as autoregressive distributed

\footnotetext{
${ }^{10}$ See, for example, Samuelson [47], Mandelbrot [29], Roll [45], and Fama [8], as well as the references cited in footnote 5 . It is important to note that unitary expectations, as defined here, do not necessarily follow from "efficient markets" assumptions.

"It is worth pointing out, however, that under Muth's hypothesis the available information must include, to within a set of additive white noise disturbances, knowledge of the model generating the actual outcomes in question, so that this hypothesis is stronger than the simple notion that agents use efficiently whatever information is available; see Friedman [12]. See also Feige and Pearce [9], whose concept of "economically rational" expectations emphasizes that optimizing agents will not fully exploit information if the cost of doing so exceeds the expected benefits.

${ }^{12}$ See, for example, Lucas [26] and Sargent and Wallace [50].
} 
lags, i.e.,

(4-A) $\quad g_{i+1}^{e}=$ constant $+\sum_{\tau=0}^{\infty} \delta_{\tau} g_{t-\tau}$

where the $\delta_{\tau}$ are fixed coefficients. ${ }^{13}$ Prediction of a ruture outcome of some process on the basis of observations of the behavior of the process in the past is a familiar notion, and previous empirical researchers have often turned to it in the context of macroeconomic series in general and interest rates in particular. Several well known simple expectations mechanisms are special cases of autoregressive expectations; examples include the "naive" prediction that next period will be like last period (which requires $\delta_{0}=1$ and $\delta_{\tau}=0$ for $\tau>0$ ), and Cagan's [5] adaptive expectation of prices and Friedman's [17] representation of expected permanent income (which both require that the $\delta_{\tau}$ decline geometrically). With respect to interest rates, Keynes' [21] regressive expectations, Duesenberry's [6] extrapolative expectations, and Modigliani and Shiller's [34] short-runextrapolative/long-run-regressive combination are all examples of general autoregressive expectations.

As already noted, these three expectations hypotheses are not mutually exclusive. Given the assumptions of the efficient markets model, for example, the unitary expectation (4-U) is also the rational expectation (4-R). Similarly, as Frenkel [10] and Mussa [38] among others have noted in the context of general price inflation, if the nature of a process is such that all relevant information about it is contained in its own past realizations, then the autoregressive expectation (4-A) is also the rational expectation (4-R); for this reason some writers have referred to such general autoregressive expectations mechanisms as "partly rational" or "weak-form rational."14 Nevertheless, by construction the unitary and autoregressive expectations cannot be identical (except for the trivial case in which $\delta_{\tau}=0$ for all $\tau$ ), and even in simple models the necessary conditions for rational and autoregressive expectations to be identical are typically most restrictive.

Hence these three hypotheses-unitary, rational, and autoregressive-do constitute different perspectives on expectations formation, each with its own motivation and literature of applications. Moreover, it follows directly fren (3) that unitary/rational/autoregressive asset capital gain (holding-period yield) expectations imply corresponding unitary/rational/autoregressive asset price expectations. Hence for finite-maturity bonds purchased at par value (or for perpetuities at any price) they also imply approximately unitary/rational/ autoregressive expectations for long-term interest rates. ${ }^{15}$

\footnotetext{
${ }^{13}$ Any finite-order moving-average process can also be expressed as an equivalent infinite order autoregression.

${ }^{14}$ See, for example, Sargent [49], Rutledge [46], and McCallum [30]. See also Shiller [51] on the distinction between rational expectations and multivariate autoregressive expectations.

${ }^{15}$ Extension of the correspondence to interest rate expectations is only approximate because, given the inverse relationship between bond prices and bond yields, Jensen's Inequality implies that the two corresponding expectations cannot both be unbiased. The magnitude of this difference is usually small, however. In addition, as Lintner [23] has shown in another context, useful theoretical results can hold regardless of which side of the inverse relationship investors expect without bias.
} 


\section{THE PORTFOLIO MODEL ${ }^{16}$}

The model of investors' demand for long-term bonds, used in Section 4 to evaluate the three competing hypotheses about expectations of long-term interest rates, follows from the assumptions (a) that the investor's single-period objective is to maximize the expected utility of end-of-period wealth, given both an existing stock of savings and a new saving flow, and (b) that the investor's utility function is of a form, such as power or logarithmic function (so that there is constant relative risk aversion), which reduces to a preference ordering in terms of the means and variance-covariance structure of the perceived distributions of the several assets' uncertain returns. The first of these assumptions is especially appropriate for institutional investors like pension funds and insurance companies, which dominate investment in the U.S. bond markets. The second has become standard since the early work of Markowitz [28] and Tobin [55].

Utility functions exhibiting constant relative risk aversion, together with joint normal (or lognormal) asset return distributions, generate optimal portfolio allocations that are linear homogeneous in wealth. Further linearization, to separate the effects of asset return means and variances, yields the investor's equilibrium portfolio allocation in the form

$$
\alpha_{i t}^{*} \equiv \frac{A_{i t}^{*}}{W_{t}}=\sum_{k}^{N} \beta_{i k} r_{k t}^{e}+\sum_{h}^{M} \gamma_{i h} x_{h t}+\pi_{i}
$$$$
(i=1, \ldots, N)
$$

where $A_{i}^{*}$ is the investor's desired holding of the $i$ th asset, $W$ is the investor's total portfolio size (wealth), $r_{k}^{e}$ is the expected return on the $k$ th asset, the $x_{h}$ are any additional variables (like nonstationary variances and covariances) that are part of asset return assessments, and the $\beta_{i k}, \gamma_{i h}$, and $\pi_{i}$ are fixed coefficients which satisfy $\Sigma_{i} \beta_{i k}=0$ for all $k, \Sigma_{i} \gamma_{i h}=0$ for all $h$, and $\Sigma_{i} \pi_{i}=1$. On the assumption of universal substitutability, the $\beta_{i k}$ also satisfy $\beta_{i k}>0, i=k$, and $\beta_{i k}<0, i \neq k$.

To translate this model of desired portfolio allocation into an operational model of investors' short-run behavior in the presence of transactions costs, some model of portfolio adjustment is necessary. Moreover, it is useful to distinguish the less costly (and hence more sensitive to asset yield expectations) allocation of the current investable cash flow $\Delta W_{t}$ from the re-allocation of the existing holdings $W_{t-1}$. An adjustment model which in the long run converges to the equilibrium given by (5), but in the short run incorporates this distinction in a tractable way, is the optimal marginal adjustment model

$$
\Delta A_{i t}=\sum_{k}^{N} \theta_{i k}\left(\alpha_{k t}^{*} W_{t-1}-A_{k, t-1}\right)+\alpha_{i t}^{*} \Delta W_{t}
$$

$$
(i=1, \ldots, N) \text {, }
$$

where the $\theta_{i k}$ are fixed coefficients of adjustment satisfying $\Sigma_{i} \theta_{i k}=\bar{\theta}$ for all $k$, with $\bar{\theta}$ arbitrary.

\footnotetext{
${ }^{16}$ Since the authors have developed this portfolio model in some detail in previous work, the discussion in this section is brief. For a full development including references to the literature, see, for example, Friedman [11, 15] and Roley [44].
} 
Substituting from (5) into (6) for the specific case of long-term bonds, and successively using each of the three representations (4) for the unobservable expected bond return, yields three alternative equations for investors' short-run demand for bonds, ${ }^{17}$

$$
\begin{aligned}
\Delta B_{t}= & \pi_{B} \cdot \Delta W_{t}+\left[\sum_{k}\left(\pi_{k} \cdot \theta_{B k}\right)\right] \cdot W_{t-1}+\beta_{B B} \cdot c_{B t} \cdot \Delta W_{t} \\
& +\sum_{k \neq B} \beta_{B k} \cdot r_{k t}^{e} \cdot \Delta W_{t}+\sum_{h} \gamma_{B h} \cdot x_{h t} \cdot \Delta W_{t}-\theta_{B B} \cdot B_{t-1} \\
& -\sum_{k \neq B} \theta_{B k} \cdot A_{k, t-1},
\end{aligned}
$$

$$
\begin{aligned}
\Delta B_{t}= & \pi_{B} \cdot \Delta W_{t}+\left[\sum_{k}\left(\pi_{k} \cdot \theta_{B k}\right)\right] \cdot W_{t-1}+\beta_{B B} \cdot\left(c_{B t}+\tilde{g}_{B, t+1}-\tilde{u}_{t+1}\right) \cdot \Delta W_{t} \\
& +\sum_{k \neq B} \beta_{B k} \cdot r_{k t}^{e} \cdot \Delta W_{t}+\sum_{h} \gamma_{B h} \cdot x_{h t} \cdot \Delta W_{t}-\theta_{B B} \cdot B_{t-1} \\
& -\sum_{k \neq B} \theta_{B k} \cdot A_{k, t-1}
\end{aligned}
$$

(7-A) $\Delta B_{t}=\pi_{B} \cdot \Delta W_{t}+\left[\sum_{k}\left(\pi_{k} \cdot \theta_{B k}\right)\right] \cdot W_{t-1}+\beta_{B B} \cdot\left(c_{B t}+\sum_{\tau}^{\infty} \delta_{\tau} g_{B, t-\tau}\right) \cdot \Delta W_{t}$

$$
+\sum_{k \neq B} \beta_{B k} \cdot r_{k t}^{e} \cdot \Delta W_{t}+\sum_{h} \gamma_{B h} \cdot x_{h t} \cdot \Delta W_{t}-\theta_{B B} \cdot B_{t-1}
$$

$$
-\sum_{k \neq B} \theta_{B k} \cdot A_{k, t-1}
$$

Comparative evaluation of the empirical performance of (7-U), (7-R), and (7-A) is the principal objective of the following sections.

\section{DATA AND ESTIMATION PROCEDURES}

Before turning to the empirical evidence, it is useful to comment briefly on several aspects of the exact specification and estimation of bond demand equations (7-U), (7-R), and (7-A).

Data: The primary data source for the stock and flow quantities used to estimate these equations is the Federal Reserve System's flow-of-funds accounts $[1$, and subsequent issues $] ;{ }^{18}$ these data are seasonally adjusted and are denominated in millions of dollars. The particular long-term interest rate $c_{B}$ used is the observed new-issue yield on long-term bonds issued by utility companies

${ }^{17}$ The expressions shown here are simplified in that they omit terms, which appear in the expansion of (5) and (6), involving products with $W_{t-1}$; the coefficients of such terms-like the coefficients shown here for the linear terms $\Delta W_{v}, W_{t-1}$, and $A_{k, t-1}, k \neq B$-are sums of products of the underlying behavioral parameters and are of unknown sign a priori. By contrast, each product of a mean or (co-)variance with $\Delta \boldsymbol{W}$, bears a coefficient, identical to a single parameter from (5).

${ }^{18}$ See Friedman [11] for further details on precise definitions of variables, in particular the cash flows of life insurance companies and households. 
rated $\boldsymbol{A} a$ by Moody's Investors Service, Inc. $\boldsymbol{A} a$-rated utility bonds provide the greatest continuity, in terms of the frequency of new issues, and they are most representative of new-issue activity in the U.S. market. Previous studies of long-term interest rate determination using the term-structure approach have relied on indices of yields on either new issues or seasoned issues, but the new-issue yield is likely to be superior for several reasons including greater trading volume, fewer measurement problems, and absence of any term-coupon bias. The sample period consists of 56 quarterly observations spanning 1960:I1973 : IV.

The capital gain $g_{B}$ on bonds of finite maturity correctly depends on the movement from one time period to another of the bonds' price as in (2). For long-term bonds priced at or near par, however, the annualized consol formula

$$
g_{B, t+1}=\frac{c_{B t}-c_{B, t+1}}{c_{B, t+1}} \cdot 4
$$

provides a close approximation. Both the rational expectations (7-R) and the autoregressive expectations (7-A) specifications of bond demand rely on this approximation.

Disaggregation: The disaggregated equations described below represent the demand for (i.e., net purchases of) long-term corporate bonds by six distinct categories of investors that together hold approximately 95 per cent of all outstanding long-term corporate bonds issued in the United States (see Table I). Most of these investors hold at least some amounts of a large number of different types of assets. Since $W_{t-1}=\Sigma_{k} A_{k, t-1}$ in each case, (7) is not identifiable in the form which includes not only $W_{t-1}$ and $B_{t-1}$ but also $A_{k, t-1}$ for all $k \neq B .{ }^{19}$ The procedure used to deal with this problem was to experiment, on an individual

TABLE I

Distribution of Year-End 1975 U.S. CoRporate Bond Holdings

\begin{tabular}{lcc}
\hline \hline \multicolumn{1}{c}{ Bonds Held By: } & Amount & Percentage \\
\hline Life Insurance Companies & $\$ 105.5$ billion & $33.3 \%$ \\
Households & 65.9 & 20.8 \\
State and Local Government Retirement Funds & 60.9 & 19.2 \\
Private Pension Funds & 37.8 & 11.9 \\
Mutual Savings Banks & 17.5 & 5.5 \\
Other Insurance Companies & 12.2 & 3.8 \\
Commercial Banks & 8.6 & 2.7 \\
Mutual Funds & 4.8 & 1.5 \\
Foreign Investors & 2.6 & 0.8 \\
Brokers and Dealers & 1.4 & 0.4 \\
Total & 317.2 & 100.0 \\
\hline
\end{tabular}

NOTES: Detail may not add to total because of rounding. All data are at par value except foreign.

${ }^{19}$ Some identification problem of this kind nearly always arises in fully specified multivariate stock adjustment models; see Brainard and Tobin [3] and Smith [53]. 
equation basis, first including $W_{t-1}$ and $B_{t-1}$ only (thereby implicitly imposing the constraint that the cross-adjustment coefficients $\theta_{B k}$ are identical for all $k \neq B$ ); then including $B_{t-1}$ and all major asset groupings $A_{k, t-1}, k \neq B$, but excluding $W_{t-1}$; and finally including $W_{t-1}, B_{t-1}$, and $A_{k, t-1}$ for only some subset of $k \neq B$. Selection among these alternative constrained subspecifications depended on goodness of fit and statistical properties. With respect to the yields, the analogous procedure used was to include only some subset of yields $r_{k t}^{e}$ on alternative assets $k \neq B$.

Other than long-term bonds, the major asset holdings of these six categories of investors fall into three classes: (i) short-term liquid assets such as Treasury bills or commercial paper, (ii) mortgages, and (iii) equities. In addition to a representation of the expected holding-period yields on bonds, $r_{B}^{e}$, to estimate (7) it is necessary to have a representation of the expected holding-period yields on these other assets as well. The equations presented below assume that this yield is, for short-term assets simply the observed market yield, for mortgages the observed new-issue yield (because of the instrument's illiquidity ${ }^{20}$ ), and for equities the current dividend/price ratio together with a simple distributed lag (motivated by autoregressive expectations) on recent equity capital gains. ${ }^{21}$ In addition to the nominal asset yields per se, these equations also include a distributed lag (again motivated by autoregressive expectations) on annualized percentage changes in consumer prices, to permit investors' demand for bonds to respond to inflation expectations in such a way (negatively, all other things equal) as to enforce the familiar Fisher effect.

Instrumental Variables: Since the own-yield on bonds is jointly determined with investors' bond demands (and with issuers' bond supplies, which would complete the structural model of the bond market ${ }^{22}$ ), it is necessary to use an estimation procedure that avoids the inconsistency of ordinary least-squares estimates. The set of instruments used here for deriving consistent estimators includes not only the predetermined variables in the six disaggregated bond demand equations but also those in the two disaggregated bond supply equations developed in Friedman [13]. As is often the case in multi-equation models, it is impossible to apply two-stage least squares because there are too many predetermined variables to permit ordinary least-squares estimation of the system's reduced form. The Brundy-Jorgenson [4] procedure, applied here, derives consistent estimators by using as instrumental variables the leading principal components of the full-system set of predetermined variables as well as, on an equation-by-equation basis, the single-equation sets of predetermined variables themselves.

In addition to using an instrumental variables procedure for the coupon component $c_{B t}$ of the own-yield in all three bond demand equations (7-U), (7-R),

\footnotetext{
${ }^{20}$ This assumption is equivalent to assuming that the holding period for mortgages, in contrast to other assets, is actually the mortgage's average life.

${ }^{21}$ In the empirical results either the dividend/price ratio or the capital gain lag had a coefficient significantly different from zero, but never both in the same equation.

${ }^{22}$ The structural approach to modeling interest rate behavior is implemented in Friedman [11, 13] and Roley [44].
} 
and (7-A), and for the current-period capital gain component $g_{B t}$ in (7-A), it is also necessary to use this procedure for the expected future capital gain variable $\left(\tilde{g}_{B, t+1}-\tilde{u}_{t+1}\right)$ in (7-R). As McCallum [30] and others have emphasized, in the absence of perfect foresight the rational expectations hypothesis (4-R) renders the realization $\tilde{g}_{B, t+1}$ distributed around, rather than equal to, the prior expectation $g_{B, t+1}^{e}$, thereby leading to a classical errors-in-variables problem for estimation if the actual $g_{B, t+1}$ were simply used in place of its expectation. The procedure used to estimate $(7-\mathrm{R})$ therefore replaces $\tilde{\mathrm{g}}_{B, t+1}$ with its Jorgenson-Brundy instrumented value. While any valid instrument will give a consistent estimate of the coefficient of $\tilde{g}_{B, t+1}$, this instrument will give a more efficient estimate than the commonly suggested simpler instrument based only on past realizations of $g_{B}$ to the extent that investors, in forming their expectations, actually take account of the additional information on which the instrument is based.

Distributed Lags: The estimation of the distributed lags in (7-A) presents an interesting identification problem due to the potential appearance of the same distributed lag $\Sigma_{\tau} \delta_{\tau} g_{B, t-\tau}$ in two separate nonlinear terms on the right-hand side of a single equation. ${ }^{23}$ The procedure used to identify all of the coefficients in this equation, and to ensure that the two appearances of the same distributed lag are in fact identical, is developed in Friedman and Roley [16]. In addition, the individual $\delta_{\tau}$ coefficients are (with one exception) constrained to follow a third-degree polynomial pattern with the right-hand tail of the lag constrained to pass through zero. Following Sims [52], the lead coefficient of the lag structure is free of the polynomial constraint.

\section{EVALUATING THE THREE EXPECTATIONS HYPOTHESES}

Tables II and III summarize key statistics that.result from estimating the bond demand of each of the six principal categories of bond investors under the unitary (7-U), rational (7-R), and autoregressive (7-A) expectations hypotheses.

\section{TABLE II}

Summary of Estimation Results for Bond Demand Under THReE EXPECTATIONS HYPOTHESES

\begin{tabular}{|c|c|c|c|c|c|c|}
\hline Investor Category & $\bar{R}^{2}$ & RMSE & $\bar{R}^{2}$ & ${ }_{\text {RMSE }}^{(7-R)}$ & $\bar{R}^{2}$ & $(7-\mathrm{A})$ RMSE \\
\hline Life Insurance Companies & .83 & 212 & .76 & 252 & .86 & 199 \\
\hline Other Insurance Companies & .90 & 77 & .84 & 100 & .94 & 66 \\
\hline Private Pension Funds & .66 & 203 & .52 & 260 & .70 & 198 \\
\hline State-Local Retirement Funds & .83 & 174 & .79 & 188 & .88 & 151 \\
\hline Mutual Savings Banks & .87 & 156 & .87 & 147 & .90 & 144 \\
\hline Households & .81 & 509 & .80 & 503 & .88 & 422 \\
\hline
\end{tabular}

NOTE: RMSE in millions of dollars.

${ }^{23}$ See again footnote 17 . This problem also applies to the price inflation lags in all three specifications, and the procedure described below is applied there, too. In fact, the $g_{B, t+1}^{e} \cdot W_{t-1}$ terms are excluded from the final equation specifications, but $P_{t}^{e} \cdot W_{t-1}$ terms are included. 
TABLE III

OWN-Yield RESPONSE COEFficient Estimates for Bond Demand under ThreE EXPECTATIONS HYPOTHESES

\begin{tabular}{lccc}
\hline \hline \multicolumn{1}{c}{ Investor Category } & $(7-\mathrm{U})$ & $(7-\mathrm{R})$ & $(7-\mathrm{A})$ \\
\hline Life Insurance Companies & .0973 & -.0011 & .0906 \\
& $(.0229)$ & $(.0012)$ & $(.0223)$ \\
Other Insurance Companies & .0503 & .0004 & .0646 \\
& $(.0090)$ & $(.0011)$ & $(.0090)$ \\
Private Pension Funds & .0633 & .0043 & .0687 \\
& $(.0109)$ & $(.0015)$ & $(.0117)$ \\
State-Local Retirement Funds & .1398 & -.0003 & .2091 \\
& $(.0459)$ & $(.0016)$ & $(.0468)$ \\
Mutual Savings Banks & -.0024 & -.0009 & .5467 \\
& $(.0542)$ & $(.0012)$ & $(.2133)$ \\
Households & .0300 & .0004 & .1235 \\
& $(.0178)$ & $(.0003)$ & $(.0238)$ \\
\hline
\end{tabular}

NOTE: Numbers in parentheses are estimated standard errors.

Table II shows each estimated equation's coefficient of determination $\left(\bar{R}^{2}\right)$ and root-mean-square error of simulation (RMSE), both adjusted for degrees of freedom. These fit statistics are important in cross-hypothesis comparisons because, unlike the $t$ statistics for the estimates in Table III, they are analogous to $F$ statistics, and hence admit valid inferences even in the presence of multicollinearity among asset yields. For equations estimated by an instrumental variables procedure, the root-mean-square simulation error (which relies on the actual values of all right-hand-side variables) is a better measure of statistical performance than is the estimated standard error (which relies on instrumented values of right-hand-side variables). ${ }^{24}$

Consistently for all six investor categories, the autoregressive expectations hypothesis (7-A) provides the best explanation of the data. Of the other two hypotheses, unitary expectations (7-U) ranks second for four investor categories, and rational expectations (7-R) for two.

Table III shows the estimated values and standard errors of the coefficient $\beta_{B B}$, which indicates the responsiveness of bond demand to the expected own-yield $r_{B}^{e}$, for the three alternative expectations hypotheses, for each category of investors. ${ }^{25}$

${ }^{24}$ In (7-R) the probability limits of the root-mean-square errors include an additional term, in comparison to the other specifications, due to the errors-in-variables properties associated with using the observed ex post $g_{B, 1+1}$ value in place of the true rational expectation $g_{B, t+1}^{e}$. Following Griliches and Ringstad [18], it is possible to obtain a consistent estimate of the resulting bias and to adjust each RMSE value for (7-R) so as to render it comparable to the RMSE values for other specifications. The resulting adjustments turned out to be extremely small, however; the largest change occurred for private pension funds, for which the adjusted RMSE value was 246. As a further check, it is possible to compute for each estimated equation (7-R) the magnitude of variance of the rational expectationi.e., the variance of $\hat{u}_{t+1}$ in $(4-R)$-which would be necessary for any RMSE value for (7-R) when adjusted by the Griliches-Ringstad procedure, to equal the corresponding RMSE value for $(7-A)$. The required var $\left(\dot{u}_{t+1}\right)$ turned out to be no less than $10^{7}$ for any of the six estimated (7-R) equations and was in some cases greater than $10^{11}$.

${ }^{25}$ Because of the instrumental variables estimation procedure, the standard error ratios are asymptotically distributed as $t$ statistics but dre not necessarily distributed as $t$ statistics in small samples. 
Since these response coefficients provide the crucial link between the different expectations hypotheses and investors' demand for bonds, they merit close inspection.

Once again, the evidence favors the autoregressive expectations hypothesis. Consistently for all six investor categories, autorégressive expectations (7-A) yields $\hat{\beta}_{B B}$ estimates significantly different from zero at high confidence levels, with the anticipated positive sign. Moreover, with the exception of mutual savings banks (for which the $\hat{\beta}_{B B}$ value is surprisingly large), these estimates are all of plausible magnitude. The $\hat{\beta}_{B B}$ value for non-life insurance companies, for example, indicates that a one percentage point increase in the expected holding-period own-yield on bonds, with all other things equal, would lead these investors to increase by an absolute six per cent (for example, from 40 per cent to 46 per cent) the desired fraction of their portfolios to be held in bonds, while the $\hat{\beta}_{B B}$ value for state and local government retirement funds indicates a 21 per cent response. The $\hat{\beta}_{B B}$ estimates for the other three investor categories lie between these two values.

Unitary expectations (7-U) performs almost as well as autoregressive expectations on this count, yielding $\hat{\beta}_{B B}$ estimates that differ from zero at high confidence levels, with the anticipated positive sign, for four investor categories; one more is marginal. (The missing category is mutual savings banks, for which the estimate under the autoregressive hypothesis is also somewhat suspect.) By contrast, rational expectations $(7-\mathrm{R})$ yields a $\hat{\beta}_{B B}$ estimate significantly different from zero at high confidence levels for only one investor category and with marginal significance for only one more; and the values of these two estimates seem implausibly small.

It is also interesting to contrast the results shown in Tables II and III, which compare the three expectations proxies' respective relation to bond demands, with their respective relation to the actual holding-period own-yield on bonds observed ex post. Over the sample period the simple correlation between the actual own-yield and the unitary expectation (that is, just the coupon rate) was.13. The simple correlations between the actual own-yield and the respective rational expectations (that is, the coupon rate plus the fitted values from the first-stage regression of the actual capital gain on the full instrument set) varied from a low of .64 for mutual savings banks to a high of .83 for households. The simple correlations between the actual own-yield and the respective autoregressive expectations (that is, the coupon rate plus the value implied by solving out the capital gain distributed lags) were clustered between .15 and .16 except for private pension funds (.12) and state-local retirement funds (only .06). Hence the sharply different relative performance of the three expectations proxies in explaining movements in bond demands does not simply reflect a difference in the proxies' respective ability to reproduce the actual own-yield on bonds. Instead, the comparison goes strongly the other way.

Table IV focuses more rigorously on the evaluation of the three competing expectations hypotheses by providing $F$ statistics for two pairwise comparisons. First, since unitary expectations is a nested hypothesis within autoregressive expectations, it is straightforward to test the null hypothesis (7-U) against the 
TABLE IV

F Statistics for PaIRwise Comparisons of Bond Demand under Three EXPECTATIONS HYPOTHESES

\begin{tabular}{llllll}
\hline \hline \multicolumn{1}{c}{ Investor Category } & \multicolumn{2}{c}{$(7-\mathrm{A})$ versus $(7-\mathrm{U})$} & \multicolumn{3}{c}{$\left(7-\mathrm{R}^{\prime}\right)$ verzus $(7-\mathrm{U})$} \\
\hline Life Insurance Companies & $3.60^{\mathrm{b}}$ & $(4,42)$ & & 1.12 & $(1,45)$ \\
Other Insurance Companies & $9.33^{\mathrm{a}}$ & $(4,41)$ & 0.54 & $(1,44)$ \\
Private Pension Funds & $2.96^{\mathrm{b}}$ & $(3,45)$ & 2.99 & $(1,47)$ \\
State-Local Retirement Funds & $8.55^{\mathrm{a}}$ & $(3,44)$ & 0.06 & $(1,46)$ \\
Mutual Savings Banks & $4.56^{\mathrm{a}}$ & $(4,46)$ & 0.97 & $(1,49)$ \\
Households & $7.53^{\mathrm{a}}$ & $(4,39)$ & 1.65 & $(1,42)$ \\
\hline
\end{tabular}

NOTES: Numbers in parentheses are degrees of freedom.

- Significant at I per cent level.

'Significant at 5 per cent level.

alternative (7-A). As the $F$ statistics in the first column of Table IV show, the evidence warrants rejecting (7-U) in favor of (7-A) for each of the six investor categories. Next, since unitary expectations is not strictly nested within rational expectations, the second column of the table shows $F$ statistics for a test of the null hypothesis (7-U) against the weaker alternative

$\left(7-R^{\prime}\right) \quad \Delta B_{t}=\ldots+\beta_{B B} \cdot c_{B t} \cdot \Delta W_{t}+\beta_{B B}^{\prime} \cdot\left(\tilde{g}_{B, t+1}-\tilde{u}_{t+1}\right) \cdot \Delta W_{t}+\ldots$

which posits a response of bond demand to the rational expectation $g_{B, t+1}^{e}$ according to coefficient $\beta_{B B}^{\prime}$, which need not equal $\beta_{B B}$ as in $(7-R)$. Here the evidence does not warrant rejecting (7-U) in favor of $\left(7-R^{\prime}\right)$ for any of the six investor categories; presumably the data would not warrant rejecting (7-U) in favor of the even stronger ( $7-R)$ either.

Unfortunately, no direct pairwise comparison is possible between autoregressive expectations and rational expectations, since neither is in any sense nested within the other. Hence the results of the two pairwise comparisons of each against unitary expectations constitute evidence favoring autoregressive expectations over rational expectations only on the (not rigorously defendable) assumption of strict transitivity.

In sum, on the basis of the fit results in Table II, the results in Table III for the coefficient of the variable which differentiates the three expectations hypotheses, and the results in Table IV for two direct pairwise comparisons, the bond demand equation subject to the autoregressive expectations hypothesis (7-A) clearly dominates. The Appendix reports the complete estimation results for bond demand equation (7-A) for the six principal categories of investors.

\section{FURTHER EVIDENCE ON EXPECTATIONS AND PORTFOLIO BEHAVIOR}

Several further aspects of the estimated bond demand equations, beyond those already discussed in Section 4, provide interesting evidence on additional questions about expectations and portfolio behavior. 
Interpreting Autoregressive Expectations: As the Appendix Table A-II shows, the estimated value of the distributed lag weight sum $\Sigma_{\tau} \delta_{\tau}$ in the bond demand equations based on autoregressive expectations is quite small, ranging from only 0.0349 for mutual savings banks to 0.1085 for households. It is possible to interpret this result in at least three ways.

First, in the context of the time-series motivation for (4-A), $\Sigma_{\tau} \delta_{\tau}<1$ indicates that investors form their expectations on the belief that long-term interest rates (actually the capital gains $\tilde{g}_{B}$ ) are stationary time series. Indeed, $F$ statistics for a test of the null hypothesis $\Sigma_{\tau} \delta_{r}=1$, reported in the first column of Table V, warrant rejecting that hypothesis at high confidence levels for all six investor categories. In this light the only surprising aspect of the estimated $\Sigma_{\tau} \hat{\delta}_{\tau}$ values is that they are so small, indicating that investors expect $\tilde{g}_{B}$ to return very rapidly to its mean value, even after a series of persistent deviations from that mean.

\section{TABLE V}

F Statistics for Additional Tests under Autoregressive AND Rational EXPECTATIONS

\begin{tabular}{lrrrrr}
\hline \hline \multicolumn{1}{c}{ Investor Category } & \multicolumn{2}{c}{$\begin{array}{c}\text { Autoregressive: } \\
\text { Test of } \Sigma_{\mathrm{r}} \delta_{\mathrm{r}}=1\end{array}$} & & \multicolumn{2}{c}{$\begin{array}{c}\text { Rational: } \\
\text { Test of } \beta_{B B}^{\prime}=\beta_{B B}\end{array}$} \\
\hline Life Insurance Companies & $12.57^{\mathrm{a}}$ & $(1,42)$ & & $20.74^{\mathrm{a}}$ & $(1,45)$ \\
Other Insurance Companies & $31.24^{\mathrm{a}}$ & $(1,41)$ & $31.17^{\mathrm{a}}$ & $(1,44)$ \\
Private Pension Funds & $33.84^{\mathrm{a}}$ & $(1,45)$ & $24.51^{\mathrm{a}}$ & $(1,47)$ \\
State-Local Retirement Funds & $14.39^{\mathrm{a}}$ & $(1,44)$ & $17.83^{\mathrm{a}}$ & $(1,46)$ \\
Mutual Savings Banks & $6.58^{\mathrm{b}}$ & $(1,46)$ & 0.63 & $(1,49)$ \\
Households & $24.63^{\mathrm{a}}$ & $(1,39)$ & & 1.66 & $(1,42)$ \\
\hline
\end{tabular}

NOTE: Numbers in parentheses are degrees of freedom.

- Significant at 1 per cent level.

bignificant at 5 per cent level.

Secondly, under the autoregressive expectations hypothesis the coefficient of $g_{B, t+1}^{e}$ in the underlying equation-i.e., what is labelled $\beta_{B B}^{\prime}$ in $\left(7-\mathrm{R}^{\prime}\right)$-and the weight sum $\Sigma_{\tau} \delta_{\tau}$ within $g_{B, t+1}^{e}$ are not both identifiable in the absence of some further constraint. ${ }^{26}$ What is estimated is the product $\left(\beta_{B B}^{\prime} \cdot \Sigma_{\tau} \delta_{\tau}\right)$. The interpretation above identifies $\Sigma_{\tau} \delta_{\tau}$ by imposing the constraint $\beta_{B B}^{\prime}=\beta_{B B}$. Conversely, given a constraint on $\Sigma_{\tau} \delta_{\tau}$ it is possible to identify $\beta_{B B}^{\prime}$ independently of $\beta_{B B}$. The most common such restriction found in the literature is the unit sum constraint $\Sigma_{\tau} \delta_{\tau}=1$, which implies that investors believe that the stochastic process generating the series in question is borderline stationary/nonstationaryi.e., that any level which has persisted for a long time will continue to persist. Under this assumption a second possible interpretation of the strong inequality $\left(\widehat{\beta_{B B}^{\prime} \cdot \Sigma_{\tau} \delta_{\tau}}\right)<\hat{\beta}_{B B}$ is simply that $\beta_{B B}^{\prime}<\beta_{B B}-$ i.e., that investors apply some discount factor to the (uncertain) capital gain component in comparison to the (known) coupon component of the return to holding bonds. Even under risk averse portfolio behavior, however, it is not clear what kind of utility function and asset return assessments would give rise to this kind of multiplicative "uncertainty

${ }^{26}$ Lucas [25] and Sargent [48], for example, have emphasized this point. 
discounting" of what is after all the mean of a distribution (unless the mean bore a systematic positive relation to a nonstationary variance).

Yet a third possible interpretation of the surprisingly strong $\Sigma_{\tau} \hat{\delta}_{\tau}<1$ result, again on the original assumption that bond demand responds equally to the coupon and expected capital gain components of the holding-period own-yield on bonds, is that investors behave as if the relevant holding period were more than a calendar quarter. The application of the chain rule of forecasting, to derive predictions of a stochastic process for more than one time period into the future, involves a convolution of the weights $\delta_{\tau}$ on themselves. If the series is stationary, so that $\Sigma_{\tau} \delta_{\tau}<1$, the value of such a convolution converges asymptotically from $\Sigma_{\tau} \delta_{\tau}$ one period in the future to zero an infinite number of periods later. In addition, even identical capital gains or losses achieved over longer real time horizons are smaller in terms of per cent per annum, the relevant unit for comparability to the coupon component of the bond return. Hence the surprisingly low $\Sigma_{\tau} \hat{\delta}_{\tau}$ estimates may be evidence that one of the assumptions of the underlying portfolio model-i.e., that investors behave as if their holding-period were a calendar quarter-is in fact incorrect. Further indirect evidence for this viewpoint comes from the disparity among the distributed lag structures reported in the Appendix for the six categories of investors. ${ }^{27}$ Instead of using different autoregressive representations to predict the value of the same process in the same future time period, the several categories of investors may actually have been using different convolutions of the same autoregressive representation to predict the values of the same process over different time horizons.

Interpreting Rational Expectations: Since the possibility of different portfolio responses to the coupon and expected capital gain components of the return to bonds is an interesting issue, it is useful to see whether a similar result emerges in the bond demand equations estimated under the rational expectations hypothesis (to which the identification problem discussed above does not apply). Since (7-R) is nested within (7-R'), it is straightforward to test the null hypothesis $\beta_{B B}^{\prime}=\beta_{B B}$ against the more general alternative of unequal responses. As the $F$ statistics shown in the second column of Table $V$ indicate, the evidence warrants rejecting $(7-R)$ in favor of $\left(7-R^{\prime}\right)$ for four of the six investor categories. Nevertheless, since the $\hat{\beta}_{B B}^{\prime}$ estimates for three of these four categories turn out on inspection to be negative, this result hardly constitutes evidence for the "uncertainty discounting" hypothesis lukewarmly suggested above.

A further useful test of the rational expectations hypothesis, in the context of the above discussion, arises from the possibility that the implicit one-quarter holding period is incorrect. If investors in fact focus on longer time horizons, the tests of the rational expectations hypothesis reported in Section 4 are invalid. Lest this hypothesis be rejected too quickly, it is necessary to perform analogous tests

\footnotetext{
${ }^{27}$ The relevant $F$ test comparing the results shown in the Appendix with analogous results based on a stacked estimation of all six equations together, so as to enforce cross-equation restrictions, rejected at high levels of confidence the hypothesis that all six lag structures are identical. While the relatively short (six quarter) lag structure found for life insurance companies may appear surprising, the more detailed work of Lintner et al. [24] apparently bore out a fifteen month lag.
} 
for rational expectations over longer holding periods. Doing so, however, produces results that are just as unfavorable to the rational expectations hypothesis as those reported in Section 4. For a one-year holding period, for example, $F$ statistics analogous to those shown in Table IV warrant rejecting the null hypothesis $(7-U)$ in favor of $\left(7-R^{\prime}\right)$ for no investor category at the 1 per cent level, and for only two at the 5 per cent level. For a two-year holding period, analogous $F$ tests again warrant rejecting $(7-U)$ in favor of $\left(7-R^{\prime}\right)$ for no investor category even at the 5 per cent level.

Response to Inflation: ${ }^{28}$ In the bond demand equations estimated under the autoregressive expectations hypothesis, reported in full in the Appendix, the coefficient estimates for the price inflation distributed lags provide evidence of behavior on the part of investors which would account for the incorporation of an "inflation premium" into nominal interest rates. In particular, the estimated sum $\Sigma_{\tau} \hat{\xi}_{\tau}$ from the distributed $\operatorname{lag} \Sigma_{\tau} \xi_{\tau} P_{t-\tau} \cdot \Delta W_{t}$, representing the inflation expectation term $P_{t}^{e} \cdot \Delta W_{t}$, are significantly different from zero, with the expected negative sign, for four of the six investor groups. ${ }^{29}$ Hence the greater the expected price inflation as inferred from recent observed price inflation, all other thingsincluding the nominal bond yield-equal, the smaller are these investors' demands for bonds. This response may represent an explicit maximization of real rather than nominal wealth; or, following Modigliani and Shiller [34], it may indicate that investors draw inferences about future interest rate movements (i.e., about future capital gains) from observations of price inflation as well as interest rates themselves.

As is the case for the autoregressive representation of the capital gain expectation, however, it is impossible to identify both the lag weight sum $\Sigma_{\tau} \xi_{\tau}$ and the coefficient $\gamma$ from (5), which indicates the portfolio response to $P^{e}$. It is interesting to note, however, that under the unit sum constraint for $\Sigma_{\tau} \xi_{\tau}$ the resulting $\hat{\gamma}$ estimates in these four equations provide some support for the precise Fisher relationship of a one-for-one increase in bond yields following an increase in the expected inflation rate. In particular, for each of the four bond demand equations including the $P_{t}^{e} \cdot \Delta W_{t}$ term, it is impossible to reject at the 10 per cent confidence level the hypothesis $\gamma=-\beta_{B B}$. Nevertheless, given both the partial equilibrium nature of these equations and the need for the identifying restriction, it is best to accept this evidence in support of Fisher only with substantial caution.

Speed of Adjustment: Although the overall "speed of adjustment" in a multiasset portfolio model like (6) properly depends on the roots of the square matrix consisting of elements $\theta_{i k}$, in the absence of estimates for the entire matrix it is interesting to examine the on-diagonal (i.e., own-stock) coefficients $\theta_{i i}$. In the bond demand equations estimated under the autoregressive expectations hypothesis, the estimates of the own-stock adjustment parameter $\theta_{B B}$ are of plausible

${ }^{28}$ See Friedman [14] for a more complete treatment of this issue.

${ }^{29}$ This term was insignificant in the equations for non-life insurance companies and private pension funds, and so it is omitted from the final specifications of these two equations. The equations both include price expectations in the term $P_{t}^{e} \cdot W_{t-1}$, but the coefficient of this term is a sum of products of parameters in the underlying model of (5) and (6); see again footnote 17. 
magnitude for all investor categories other than mutual savings banks. Furthermore, the different $\hat{\theta}_{B B}$ estimates for the different groups of investors roughly correspond to intuitive judgments of the various investors' respective speeds of portfolio adjustment based on institutional considerations. In particular, these estimates indicate that private pension funds (which are typically managed very actively) undertake the most rapid re-allocation of their existing assets, followed next by state and local government retirement funds (which are also typically managed by market professionals). By contrast, life insurance companies (whose bond portfolios are heavily concentrated in private placement loans of limited marketability) have a small $\hat{\theta}_{B B}$ estimate, indicating a much slower re-allocation process.

It is also interesting to note that, with the exception of life insurance companies and mutual savings banks, the indicated adjustment speeds are noticeably more rapid than those typically found by previous researchers. ${ }^{30} \mathrm{~A}$ plausible inference from this finding is that the familiar very slow adjustment speeds often reported confound genuine portfolio adjustment lags with slowly adjusting expectations of holding-period yields, so that explicitly separating out the expectations mechanism produces better estimates of the true speed of portfolio adjustment out of equilibrium.

\section{SUMMARY OF CONCLUSIONS}

The principal conclusion to emerge from the empirical work presented in this paper, on the demand for bonds by six major categories of U.S. investors, is that the evidence favors an autoregressive representation of investors' expectations of future bond prices-i.e., of future long-term interest rates. Both the unitary and the rational representations of investors' expectations lead to inferior results in comparison with the autoregressive model. The model based on the autoregressive expectations hypothesis does a good overall job of explaining the demand for bonds by each of the six categories of investors, and (except for mutual savings banks) ${ }^{31}$ the key individual parameter estimates are highly plausible. Moreover, in direct pairwise comparisons of nested hypotheses, the evidence consistently rejects unitary expectations in favor of autoregressive expectations, but does not reject unitary expectations in comparison to even a weakened statement of rational expectations.

The empirical work presented in this paper also leads to three further observations about the nature of investors' expectations formation and portfolio behavior:

(i) The results relying on the autoregressive representation of expectations

\footnotetext{
${ }^{30}$ In the bond demand equations presented in Friedman [11], for example-which include no expectational lags- $\hat{\theta}_{B B}$ estimates corresponding to those shown in the Appendix are (in the order of the respective appearance in the Appendix) $.149, .139, .373, .145, .122$, and .117 .

${ }^{31}$ Given the highly specific character of mutual savings banks' deposit and mortgage lending business-including, for example, the effects of Regulation $Q$ interest ceilings-it is not surprising that a general model of portfolio behavior derived largely from theoretical underpinnings suffers from serious shortcomings when applied to their bond demand.
} 
imply either (a) that investors' expectations of future bond prices (yields) are such as to anticipate a rapid return to the long-run trend even after persistent deviations from that trend, or (b) that investors' demands for bonds respond less fully to movements in the uncertain capital gain component of the holding-period yield on bonds than to the certain coupon component, or (c) that different categories of investors respond to expectations of future bond prices over different multi-period time horizons. Because the relevant part of the bond demand model is under-identified, it is not possible to determine which (or whether perhaps all) of these phenomena is responsible for the observed behavior of investors.

(ii) For four of the six investor categories examined, the evidence supports a response of bond demand to (autoregressive) price expectations in such a way (i.e., negatively) as to explain the development of a Fisherian "inflation premium" in long-term interest rates. Furthermore, the magnitude of this inflation effect is consistent with a one-for-one relationship between the expected inflation and the inflation premium.

(iii) With the exception of life insurance companies (and mutual savings banks), the evidence points to more rapid portfolio adjustments than previous researchers investigating portfolio behavior have typically found. For those investors with actively managed portfolios, the implied speed of adjustment out of equilibrium is extremely rapid.

\section{Harvard University and \\ Federal Reserve Bank of Kansas City}

Manuscript received April, 1977; revision received September, 1978.

\section{APPENDIX}

Table A-I shows the final specifications, parameter estimates, standard errors, and summary statistics for bond demand equation (7-A) estimated for each of the six categories of bond investors. ${ }^{32}$ $\bar{R}^{2}$ is the coefficient of determination adjusted for degrees of freedom, SE is the standard error of estimate, and DW is the Durbin-Watson statistic. The variable symbols are consistent for all six

TABLE A-I

Estimation Results for Bond Demand EOUATION (7-A)

Life Insurance Companies

$$
\begin{aligned}
\Delta B_{t}^{L}= & 0.05185+0.09056\left[\left(c_{B_{t}}+\sum_{\tau} \delta_{\tau} g_{B, t-\tau}\right) \cdot \Delta W_{t}^{L}\right]^{*} \underset{(0.00942)}{-0.02014 g_{E_{t}}^{e} \cdot \Delta W_{t}^{L}} \\
& (0.01789)(0.02228) \\
& +0.000283 g_{E_{t}}^{e} \cdot W_{t-1}^{L}+\sum_{\tau} \xi_{T} P_{t-\tau} \cdot \Delta W_{t}^{L}-0.1160 B_{t-1}^{L} \\
& (0.000119)
\end{aligned}
$$

$\tilde{R}^{2}=0.86 \quad \mathrm{SE}=174 \quad \mathrm{DW}=1.42$

${ }^{32}$ The equations for the two categories of insurance companies delete two quarters in one case and one quarter in the other; see Friedman [11]. 
Other Insurance Companies

$$
\begin{aligned}
& \Delta B_{1}^{0}=\underset{(0.0903)}{0.3631} W_{t-1}^{0}+\underset{(0.00899)}{0.06455}\left[\left(c_{B_{t}}+\sum_{\tau} \delta_{\tau} g_{B, t-\tau}\right) \cdot \Delta W_{1}^{0}\right]_{(0.00130)}^{*}-0.00621 g_{E t}^{e} \cdot \Delta W_{1}^{0}+\sum_{\tau} \xi_{T} P_{t-\tau} \cdot W_{t-1}^{0} \\
& -0.3981 B_{t-1}^{0}-0.3313 E_{t-1}^{0}-0.4376 M_{t-1}^{0}-0.4709 U^{0} \\
& (0.1097)^{B_{t-1}}(0.0903) \quad(0.1051)^{t-1}(0.1205) U_{t-1}^{0} \\
& \bar{R}^{2}=0.94 \quad \mathrm{SE}=56 \quad \mathrm{DW}=1.20
\end{aligned}
$$

$$
\begin{aligned}
& \text { Private Pension Funds } \\
& \Delta B_{t}^{P}=\underset{(0.1238)}{0.5834} W_{t-1}^{P}+\underset{(0.01171)}{0.06873}\left[\left(c_{B_{t}}+\sum_{\tau} \delta_{\tau} g_{B, t-\tau}\right) \cdot \Delta W_{T}^{P}\right]^{*}-0.000122 g_{E t}^{e} \cdot W_{t-1}^{P} \\
& +\sum_{T} \xi_{T} P_{t-\tau} \cdot W_{t-1}^{P}-0.7893 B_{t-1}^{P}-0.6018 E_{t-1}^{P} \\
& \begin{array}{lll}
\bar{R}^{2}=0.70 & \mathrm{SE}=180 & \mathrm{DW}=2.47
\end{array}
\end{aligned}
$$

$$
\begin{aligned}
& \text { State-Local Retirement Funds }
\end{aligned}
$$

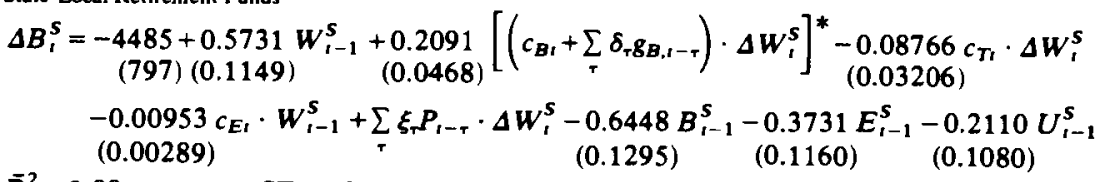

$$
\begin{aligned}
& \bar{R}^{2}=0.88 \quad \mathrm{SE}=130 \quad \mathrm{DW}=2.20
\end{aligned}
$$

Mutual Savings Banks

$$
\begin{aligned}
& \Delta B_{I}^{M}=\underset{(0.2133)}{0.5467}\left[\left(c_{B_{1}}+\sum_{\tau} \delta_{\tau} g_{B, r-\tau}\right) \cdot \Delta W_{T}^{M}\right]_{(0.1435)}^{*} \underset{(0.3258}{-0.25} c_{C_{t}} \cdot \Delta W_{I}^{M} \\
& +\sum_{\tau} \xi_{T} P_{t-\tau} \cdot \Delta W_{t}^{M}-0.03372 B_{t-1}^{M} \\
& \begin{array}{lll}
\bar{R}^{2}=0.90 & \mathrm{SE}=129 & \mathrm{DW}=1.83
\end{array}
\end{aligned}
$$

\section{Households} $\Delta B_{t}^{H}=\underset{(2085)(0.00110)}{7761-0.00760} W_{t-1}^{H}+\underset{(0.0238)}{0.1235}\left[\left(c_{B_{t}}+\sum_{\tau} \delta_{\tau} g_{B_{1}, \tau}\right) \cdot \Delta W_{t}^{H}\right] \underset{(0.02695)}{-0.06485} c_{E t} \cdot \Delta W_{t}^{H}$

$+0.00238 c_{E_{t}} \cdot W_{t-1}^{H}-0.05509 c_{T_{1}} \cdot \Delta W_{t}^{H}+0.000842 c_{T} \cdot W_{t-1}^{H}-0.5316 B_{t-1}^{H}$ $\begin{array}{llll}(0.90245) & (0.01283) & (0.000213) & (0.1051)\end{array}$

$-0.1185 U_{t-1}^{H}+\sum_{T} \xi_{T} P_{1-\tau} \cdot \Delta W_{t}^{H}-0.02601 \sum_{(0.0311)} \xi_{T} P_{t-\tau} \cdot W_{t-1}^{H}$
$(0.00709)^{\top}$

$\bar{R}^{2}=0.88$

SE $=349$

$\mathrm{DW}=2.20$

Summary of Variable Symbols:

$B$ : holdings of long-term corporate bonds;

$E$ : holdings of corporate equities;

$M$ : holdings of municipal bonds;

$U$ : holdings of U.S. government securities;

$W$ : total holdings of financial assets;

$c_{B}$ : current yield on new issues of corporate bonds (Aa utilities);

$c_{C}$ : current yield on new commercial mortgages (ALIA series);

$c_{E}$ : current yield on equities ( $\mathrm{S} \& \mathrm{P}$ dividend/price ratio);

$c_{T}$ : yield on Treasury bills;

$g_{B}$ : capital gain (or loss) on corporate bonds;

$g_{E}^{e}$ : expected capital gain (or loss) on equities (four-quarter moving average of percentage price change of common stocks);

$P$ : change in consumer price index. 


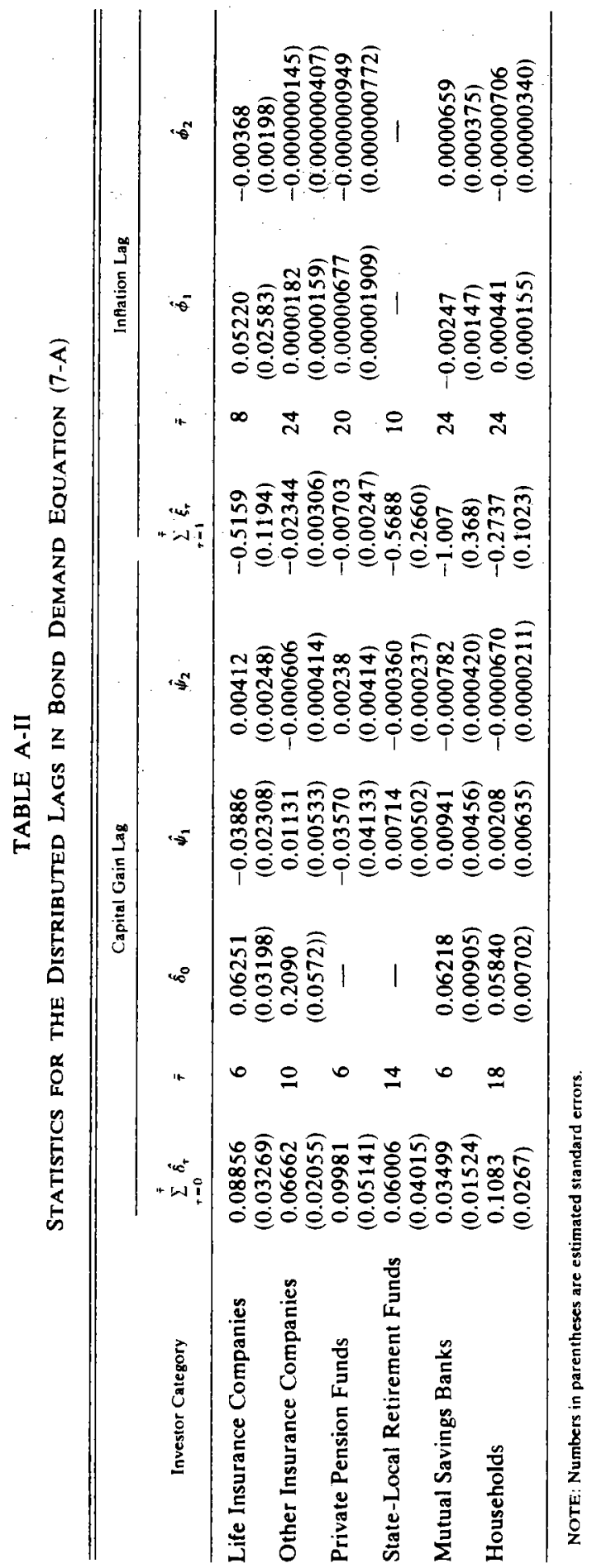


equations, with letter superscripts indicating distinctions among corresponding variables for the respective investor categories. Asterisk superscripts indicate terms for which an equation is estimated using fitted values of the variable from the first stage of the instrumental variables procedure. ${ }^{33}$

Table A-II shows for each equation the sum of the distributed lag weights $\Sigma_{r} \hat{\delta}_{\tau}$ which define the autoregressive expectation (4-A) of the capital gain component of the own-yield on bonds, the lag length $\bar{\tau}$, the independently estimated $\hat{\delta}_{0}$, and the coefficients of the two associated polynomial variables, $\hat{\psi}_{1}$ and $\hat{\psi}_{2} \cdot{ }^{34}$ For private pension funds and state and local government retirement funds, the $\hat{\delta}_{0}$ estimate did not differ significantly from zero, and so $g_{B t}$ is omitted from the lag structure for these two investor groups. The table also shows the corresponding information for the sum of the distributed lag weights $\xi_{T}$ which define the autoregressive expectation of the annualized percentage change of prices (the consumer price index) analogously to (4-A), and for the coefficients of the two associated polynomial variables, $\hat{\phi}_{1}$ and $\hat{\phi}_{2} .{ }^{35}$ The unconstrained $\hat{\xi}_{0}$ estimate did not differ significantly from zero in any equation, and so $P_{t}$ is omitted from the lag structure throughout.

\section{REFERENCES}

[1] BoARd of Governors of THE Federal Reserve SYSTEM: Flow of Funds Accounts 1945-72. Washington, D.C., 1973.

[2] BoX, GEORGE E.P., AND GWILYM M. JENkINS: Time Series Analysis for Forecasting and Control. San Francisco: Holden-Day, Inc., 1970.

[3] Brainard, William C., AND James Tobin: "Pitfalls in Financial Model-Building," American Economic Review, 57 (1968), 99-122.

[4] BRUndy, James M., AND DALE W. JoRgenson: "Efficient Estimation of Simultaneous Equations by Instrumental Variables," Review of Economics and Statistics, 53 (1971), 207-224.

[5] Cagan, Phillip: "The Monetary Dynamics of Hyperinflation," in Studies in the Quantity Theory of Money, ed. by M. Friedman. Chicago: University of Chicago Press, 1956.

[6] Duesenberry, JAMEs S.: Business Cycles and Economic Growth. New York: McGraw-Hill Book Company, Inc., 1958.

[7] Fama, Eugene F.: "Multiperiod Consumption-Investment Decisions," American Economic Review, 60 (1970), 163-174.

[8] - "Efficient Capital Markets: A Review of Theory and Empirical Work," Joumal of Finance, 25 (1970), 383-417.

[9] Feige, Edgar L., and Douglas K. Pearce: "Economically Rational Expectations: Are Innovations in the Rate of Inflation Independent of Innovations in Measures of Monetary and Fiscal Policy?" Joumal of Political Economy, 84 (1976), 499-522.

[10] Frenkel, JACOB A.: "Inflation and the Formation of Expectations," Joumal of Monetary Economics, 1 (1975), 403-421.

[11] Friedman, Benjamin M.: Financial Flow Variables and the Short-Run Determination of Long-Term Interest Rates," Joumal of Political Economy, 85 (1977), 661-689.

${ }^{33}$ Because of the nonlinear way in which both yield and non-yield variables enter the model, all such terms are products. The correct instrument to use in each such case, for purposes of deriving consistent estimators, is the first-stage fitted value of the entire product; this procedure is used here.

${ }^{34}$ For private pension funds and state-local retirement funds, the two polynomial variables do not differ significantly from zero individually but do differ significantly from zero jointly. The $F$ statistic values are 2.79 (with 3 and 45 degrees of freedom) and 8.30 (with 3 and 44 degrees of freedom), respectively.

${ }^{35}$ For other insurance companies and private pension funds, the two polynomial variables do not differ significantly from zero individually but do differ significantly from zero jointly. The $F$ statistic values are 42.5 (with 3 and 41 degrees of freedom) and 23.0 (with 3 and 45 degrees of freedom), respectively. Preliminary experimentation with the equation for state and local government retirement funds failed to indicate a value of $\overline{\boldsymbol{\tau}}$ for which the polynomial variables were significantly different from zero, given the other constraints imposed. Instead of searching extensively either over many values of $\bar{\tau}$ or over alternative (weaker) constraints on the lag, the procedure used was simply to replace the polynomial distributed lag by a rectangular lag for this one equation. 
[12] — " Optimal Expectations and the Extreme Information Assumptions of 'Rational Expectations' Macromodels," Joumal of Monetary Economics, 5 (1979), 23-41.

[13] — : "Substitution and Expectation Effects on Long-Term Borrowing Behavior and LongTerm Interest Rates," Journal of Money, Credit and Banking, 11 (1979), 131-150.

[14] - "Price Inflation, Portfolio Choice and Nominal Interest Rates," American Economic Review, forthcoming.

[15] — : The Effect of Shifting Wealth Ownership on the Term Structure of Interest Rates: The Case of Pensions," Ouarterly Journal of Economics, forthcoming.

[16] Friedman, Benjamin, M., and V. VANCE Roley: "Identifying Identical Distributed Lag Structures by the Use of Prior Sum Constraints," Annals of Economic and Social Measurement, 6 (1977), 429-444.

[17] Friedman, Milton: A Theory of the Consumption Function. Princeton: Princeton University Press, 1957.

[18] GRILICHES, ZVI, AND V. RINGSTAD: Economies of Scale and Form of the Production Function. Amsterdam: North-Holland Publishing Company, 1971.

[19] Hamburger, Michael J., AND Elliotr N. Platt: "The Expectations Hypothesis and the Efficiency of the Treasury Bill Market," Review of Economics and Statistics, 57 (1975), 190-199.

[20] Hicks, John R.: Value and Capital. London: Oxford University Press, 1939.

[21] KeYNES, JOHN MAYNARD: The General Theory of Employment Interest and Money. New York: Harcourt Brace \& World, Inc., 1936.

[22] LeijonhufVud, AXEL: On Keynesian Economics and the Economics of Keynes. New York: Oxford University Press, 1968.

[23] LinTNER, JOHN: "The Aggregation of Investors' Diverse Judgments and Preferences in Purely Competitive Security Markets," Journal of Financial and Quantitative Analysis, 4 (1969), 347-400.

[24] Lintner, John, Thomas Piper, And Peter Fortune: "Forward Commitment Decisions of Life Insurance Companies for Investments in Bonds and Mortgages," in Explorations in Economic Research, 4 (1978), 595-644.

[25] LuCAS, ROBERT E.: "Econometric Testing of the Natural Rate Hypothesis," in The Econometrics of Price Determination, ed. by O. Eckstein. Washington: Board of Governors of the Federal Reserve System, 1972. [26] - "An Equilibrium Model of the Business Cycle," Journal of Political Economy, 83 (1975),

[27] LUTZ, FRIEDRICH A.: "The Structure of Interest Rates," Ouarterly Journal of Economics, 54 (1940), 36-63.

[28] MARKOWITZ, HARRY: "Portfolio Selection," Journal of Finance, 7 (1952), 77-91.

[29] MANDElbROT, BenOIT: "Forecasts of Future Prices, Unbiased Markets and Martingale Models," Journal of Business, 39 (1966 Supplement), 242-255.

[30] MCCAllum, B. T.: "Rational Expectations and the Natural Rate Hypothesis: Some Consistent Estimates," Econometrica, 44 (1976), 43-52.

[31] Meiselman, David: The Term Structure of Interest Rates. Englewood Cliffs: Prentice-Hall, 1962.

[32] Melton, William C.: "Simultaneous Restricted Estimation of a New Model of Commercial Bank Portfolio Behavior," Ph. D. thesis, Harvard University, 1976.

[33] MINCER, JACOB: "Models of Adaptive Forecasting," in Economic Forecasts and Expectations, ed. by J. Mincer. New York: Columbia University Press, 1969.

[34] MOdigliani, FRANCO, AND ROBERT J. SHILleR: "Inflation. Rational Expectations, and the Term Structure of Interest Rates," Economica, 40 (1973), 12-43.

[35] Modigliani, Franco, and Richard Sutch: "Innovations in Interest Rate Policy," American Economic Review, 56 (1966), 178-197.

[36] -: "Debt Management and the Term Structure of Interest Rates: An Empirical Analysis of Recent Experience," Journal of Political Economy, 75 (1967), 569-589.

[37] Mossin, Jan: "Optimal Multiperiod Portfolio Policies," Journal of Business, 41 (1968), 215-229.

[38] MuSSA, MiChaEl: "Adaptive and Regressive Expectations in a Rational Model of the Inflationary Process," Journal of Monetary Economics, 1 (1975), 423-442.

[39] MUTh, John F: "Rational Expectations and the Theory of Price Movements," Econometrica, 29 (1961), 315-335. 
[40] Nelson, Charles R.: The Term Structure of Interest Rates. New York: Basic Books, Inc., 1972.

[41] Nerlove, MARC: "Distributed Lags and Unobserved Components in Economic Time Series," in Ten Economic Studies in the Tradition of Irving Fisher, by W. Fellner et al. New York: John Wiley \& Sons, Inc., 1967.

[42] Phillips, Llad, AND John Pippenger: "Preferred Habitat vs. Efficient Markets: A Test of Alternative Hypotheses," Federal Reserve Bank of St. Louis, Review, 58 (1976), 11-19.

[43] — : "The Term Structure of Interest Rates in the FRB-MIT-PENN Model: Reality or Illusion?" Journal of Money, Credit and Banking, 11 (1979), 151-164.

[44] Roley, V. VANCE: "A Structural Model of the U.S. Government Securities Market," Ph.D. dissertation, Harvard University, 1977.

[45] ROLL, RichaRD: The Behavior of Interest Rates. New York: Basic Books, 1970.

[46] RUTLEDGE, JoHN: A Monetarist Model of Inflationary Expectations. Lexington: D. C. Heath and Company, 1974.

[47] Samuelson, Paul A.: "Proof that Properly Anticipated Prices Fluctuate Randomly," Industrial Management Review, 6 (1965), 41-49.

[48] Sargent, Thomas J.: "A Note on the 'Accelerationist' Controversy," Journal of Money, Credit and Banking, 3 (1971), 721-725.

[49] —_: "Rational Expectations, the Real Rate of Interest, and the Natural Rate of Unemployment," Brookings Papers on Economic Activity, 2 (1973), 429-472.

[50] Sargent, Thomas J., and NeIl Wallace: " 'Rational' Expectations, the Optimal Monetary Instrument, and the Optimal Money Supply Rule," Journal of Political Economy, 83 (1975), 241-254.

[51] SHILleR, ROBERT J.: "Rational Expectations and the Dynamic Structure of Macroeconomic Models," Journal of Monetary Economics, 4 (1968), 1-44.

[52] Sims, Christopher A.: "Distributed Lags," Frontiers of Quantitative Economics, Vol. II, ed. by M. Intriligator and D. Kendrick. Amsterdam: North-Holland Publishing Company, 1974.

[53] SmIth, GARY: "Pitfalls in Financial Model Building: A Clarification," American Economic Review, 65 (1975), 510-516.

[54] StiglitZ, J. E.: "A Consumption-Oriented Theory of the Demand for Financial Assets and the Term Structure of Interest Rates," The Review of Economic Studies, 37 (1970), 321-351.

[55] ToBIN, JAMES: "Liquidity Preference as Behavior Toward Risk," Review of Economic Studies, 25 (1958), 65-86. 